\title{
Develop a Participatory Model in Nutrition Education to Prevent Childhood Obesity
}

\author{
Louisa Ming Yan Chung*, Joanne Wai Yee Chung \\ Department of Health and Physical Education, The Hong Kong Institute of Education, Hong Kong, China \\ Email: ${ }^{\text {chungmy@ied.edu.hk, joannechung@ied.edu.hk }}$
}

Received 28 January 2015; accepted 10 April 2015; published 20 April 2015

Copyright (C) 2015 by authors and Scientific Research Publishing Inc.

This work is licensed under the Creative Commons Attribution International License (CC BY).

http://creativecommons.org/licenses/by/4.0/

c) (†) Open Access

\section{Abstract}

Purpose: To investigate the effect of nutrition education and the engagement of students, parents and teachers in addressing school-specific environmental influences in eating problem. Design: This study adopted the action research process of diagnosing, action planning, taking action, evaluating, and specifying learning. Each of obese and non-obese male and female students was randomly selected based on physical screening based on obesity criteria. Dietary intake records were taken over seven days as the pre-intervention period. These four students, one of each of their parents and the teacher from the primary school, were given 3 sessions of nutrition education. After the nutrition education, dietary intake records were taken over the subsequent 7 days as the post-intervention period. Lunch observation and lunch menu review were included to identify eating problem of primary school children in school level. Findings: Students were found to consume less whole grains and more food items belonged to the "limited" and "strongly discouraged" as set in government lunch guidelines. Students' dietary intakes before and after the nutrition education were found improved in their energy intake $(p=0.012)$, total fat, saturated fat, calcium, sodium, and cholesterol. Conclusion: A participatory model in elementary nutrition education could be effective.

\section{Keywords}

Action Research, Nutrition Education, Childhood Obesity, A Participatory Model

\section{Introduction}

The rates of obesity have escalated sharply in both developed and developing countries in the last two decades

"Corresponding author. 
[1] [2]; therefore, the prevention of childhood obesity is a global priority. The definition of obesity varies with the diagnostic criteria to be adopted in children. Literature has four commonly adopted diagnostic criteria, namely, the IOTF criteria in 2000 [3], COTF criteria in 2004 [4], Growth Charts for the United States criteria [5], and the HKGS criteria [6]. In Hong Kong, the childhood obesity is referred to specific weight by age and sex higher than $120 \%$ of the median weight for height. In 1997/1998, the rate of obesity among primary school children was $16.4 \%$ and it increased to $18.7 \%$ in $2004 / 2005$ and further to $20.2 \%$ in $2006 / 2007$ [7]. As reported by the Hong Kong Government, 17\% of surveyed children under age 5 were overweight in 2010 [8] and the childhood obesity was reasonable to be projected to $25 \%$ by 2013 [9].

In fact, overweight and obese problems in childhood and adolescence increase the risk of chronic diseases, such as heart disease, cancer, and diabetes [10]. They are also known to have a significant adverse impact on psychological well-being, causing many children to be negatively stereotyped [8] [11] and to experience low self-esteem and negative self-image [12] [13]. There are many scientific facts showing that being overweight or obese results from a complex interaction between genes and the environment, which is compounded by longterm energy imbalance [14]-[17]. Our understanding of how and why childhood obesity develops is incomplete because it involves social influences such as eating behaviour, eating speed, school policy, and family influence. The role of social influences, particularly those related to school settings, raises our concern to childhood obesity. With primary schools changing their teaching schedule from half day to whole day in these few years, school lunch dominates the meal time in childhood that the nutrients in school lunch place an important role in children's health. Therefore, children's eating behaviour, school policy and the selection of school lunch providers may contribute to their overweight problem. At present, it is not common for primary school teachers engaged in nutrition education. However, nutrition education becomes vitally important if we hope the children to grow up healthily and build up healthy eating behaviours. In this connection, it is important for the health educators to implement nutrition education in a school setting and to design pedagogy which engages all stakeholders in the participatory approach. Therefore, it is the goal of this action research to develop pedagogy in nutrition education which aims to reduce obesity among school children.

\section{Theoretical Framework}

The Team adopted the action research process of Gerald [18]. An action research involves the integration of research and action. Specifically, the researchers learn from experience by participating in the self-reflective enquiry, then improving rationality and justice of their own practices, understanding the situations and finally implementing the changes [19]. One of the key approaches that action research served to the participants is the empowering of them to be the co-researchers [20], so as to make the action research contextual, meaningful and relevant to the practice [19]. In regards to this theoretical basis, a nutrition education should target to tackle the issue of childhood obesity in a school setting and an action research facilitates theory, practice and outcome by engaging all stakeholders in the reflective process. This study aims to develop nutrition education pedagogy in addressing the healthy eating and childhood obesity issue in primary schools (Figure 1).

\section{Method}

\subsection{Design}

It was an action research in which schoolchildren, teachers and parents in one primary school in Hong Kong actively participated in the research process to design and develop nutrition education pedagogy.

\subsection{Procedure}

\subsubsection{Stage 1: Diagnosing}

The purpose of this stage was to determine the extent of obesity among the school children. In this stage, all schoolchildren of Primary 6in a school were recruited to have a preliminary obesity assessment. The assessment included demographic data, body weight, body height, and fat percentage. Obese schoolchildren were then identified based on the HKGS criteria [19]. Randomly, one obese and one non-obese male and female student were selected to participate in the action research. Their parents were also invited to join the research team, together with one school teacher to learn and practise the nutrition education. Prior to the action research, briefing sessions were held so as to ensure all participants (schoolchildren, parents and teachers) understood the purpose and 


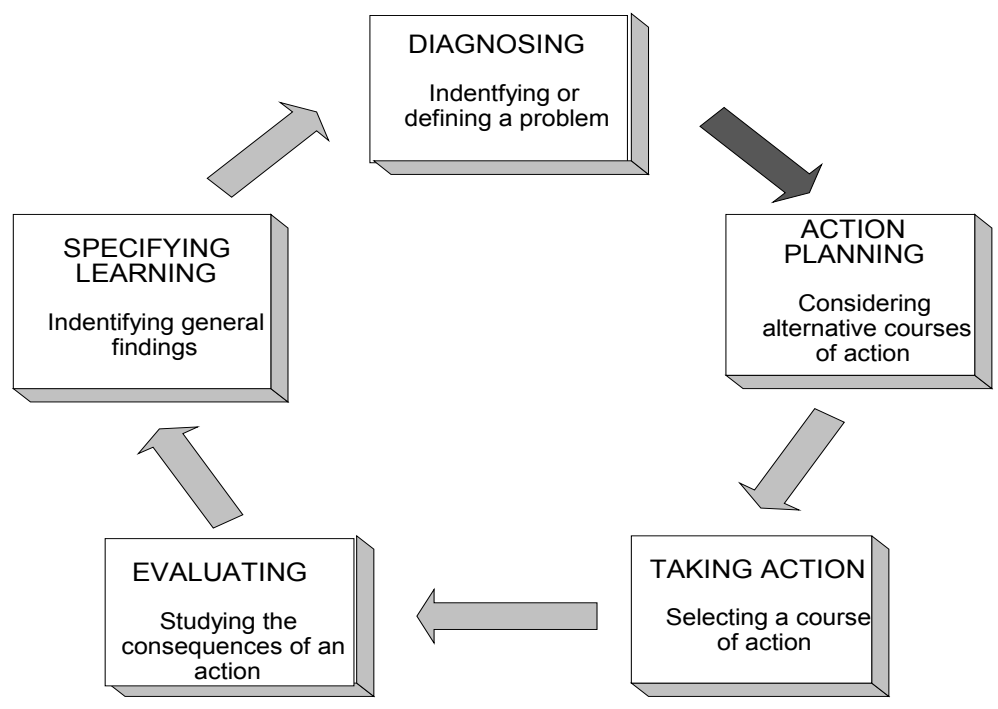

Figure 1. Action research model adapted from Susman (1983).

details of the action plan.

A checklist of lunch observation was developed by the research team (Appendix 1). This was valuable to assess whether the social factors during the lunch time were interrelated in the school environment and if they influenced the issue of childhood obesity. Observation on school lunch was conducted for these four participated children by two researchers in the research team. The observation focused on the speed of eating and their eating habits (e.g. share food, interaction during lunch and roles of schoolchildren and teachers) because these social factors could contribute to the obesity in a school environment. A checklist developed based on the observation results would be critical in bringing the possibly eating issues to the stakeholders and this would be a main pedagogical content to the nutrition education. Meal menu provided by the catering services would also be evaluated by the research team. The meal menu ordered by the four participated schoolchildren in the past one month were assessed according to the "Nutritional Guidelines on School Lunch for Primary School Students" produced by Department of Health [7].

\subsubsection{Stage 2: Action Planning}

The purpose of this stage was to generate and consider alternative courses of action. In this stage, the research team presented the findings in stage 1 to the schoolchildren, teachers and the parents of the four participated children. Views focusing on interpretation of the issues and causes of obesity were discussed so as to gain insights in devising nutrition education for the next stage. The overarching goal of the nutrition education to the students was a blended learning in both action and reflection.

\subsubsection{Stage 3: Taking Action}

The purpose of this stage was to implement the plan that was generated based on discussion in stage 2. During the implementation period, the research team served as a resource for queries and support. This implementation lasted for two weeks. For these four students, dietary intake records were taken over seven days as the pre-intervention period. These four students were given 3 sessions of nutrition education, each session lasting 1.5 hours. The content of the nutrition education covered the principles of healthy eating, the concept of healthy food choice and portion size and the eating behavior that regarded as factors possibly causing obesity. The four students, one of each of their corresponding parents and the teacher in-charge from the primary school were present at the educational sessions. After the nutrition education, dietary intake records were taken over the subsequent 7 days as the post-intervention period.

The four schoolchildren were requested to record their daily dietary records by a web-based electronic platform. This electronic platform provides accurate and reliable food images [21] and has demonstrated high usability [22]. Daily telephone interviews for recording the number of portions taken for each food were done by a researcher. A qualified nutritionist evaluated energy and nutrient values for the foods in the form of digital pho- 
tos uploaded to the electronic platform. Daily energy requirement (taking into consideration gender, age, body height, body weight and daily physical activity level), daily energy consumption, and 8 nutrient values (carbohydrate, protein, total fat, saturated fat, calcium, sugar, cholesterol, dietary fibre) were feedback to the electronic platform to allow the four schoolchildren to reflect their diet shown as reports. Comments on energy balance and nutrient balance shown in the reports would encourage the schoolchildren to modify their food choices and portion sizes. This reflective learning aims to improve children's eating behavior towards the healthier way.

\subsubsection{Stage 4: Evaluating}

The purpose of this stage was to provide analysed data as the outcome of the action implemented. The research team summarised the findings and presented to the participants as a review exercise. A major activity of this stage was to involve the participants to feedback their comments in the educational activities. This was useful for the educators to document the expected and unexpected findings in the process and the impact of activities was prioritized based on the feedback from the participants.

\subsubsection{Stage 5: Specifying Learning}

The purpose of this stage was to reinforce the learning needs identified in the action research. Through the reflection, questioning and review of the process, knowledge gaps of students were identified from the findings. These identified learning needs were useful for the next cycle of action research for continuous improvement in solving the problem - that is, in reducing obesity among school children.

\section{Results}

A total of 58 students participated in the baseline physical measurement. Of these, 12 were found to be obese. One male and 1 female student who were obese and 1 male and 1 female student who were not obese were chosen randomly for the action research.

\subsection{Lunch Observation}

A field observation checklist was developed and tested three times in three different days. Average measure intraclass correlation coefficient (ICC) was calculated to find the reliability for all the observers averaged together. The inter-rater correlation coefficient was $0.6(\mathrm{p}=0.013)$ at confidence level of $95 \%$. The four students were observed with regard to their eating behaviour at lunch with two observers for each student. Various lunch boxes were ordered by the students and provided by the lunch provider. The average number of food items in the lunch box was 3. The students spent an average of $9.75(\mathrm{SD}=1.5)$ minutes to finish their meals and one of them left about $20 \%$ food uneaten. Only one student drank approximately $200 \mathrm{mls}$ water after the meal. All students remained in their seats during meal time although three of them were distracted to different extents during their meal time. None of them appeared tense, and two looked happy and enjoyed the food.

\subsection{One-Month School Lunch Review}

In Hong Kong, the usual practice of students' lunch boxes was ordered in monthly basis. Order forms listed with 4 different meal menus on every school day were distributed to students' parents. Students and their parents were asked to choose the lunch boxes from the meal menu and returned the order forms before the next month. In this action research, the meal menu and the four students' ordered lunch boxes in the previous month were reviewed by the research team. The evaluation criteria follow the recommendations documented by the Hong Kong Department of Health (Appendix 2). There were seventeen lunch meals ordered by each participated student and the number of meals satisfying each criterion of healthy lunch for each student was counted. In summary, no student made choices that met all five criteria of a healthy lunch. The problem of consuming whole grains was severe because only 3 students picked the whole grains lunch menu in 4 out of 68 meal menu provided by the vendor. On the contrary, all four students picked the "limited" food items on half of the lunch days and the "strongly discouraged" food items on the lunch menu (Table 1).

\subsection{Pre-Post Dietary Analysis}

The means and standard deviations of energy and nutrients for the four students before and after the nutrition 
education are depicted in Table 2. It was found that the daily energy consumption was higher than the daily energy requirement at the baseline. However, after the intervention, the daily energy consumption was similar to the daily energy requirement. Although the pre-post daily energy balance was not significant at the group level, it was significant at the individual level (Table 3). Table 4 indicated the passing rate of each student in satisfying criteria in the concept of balanced diet. The results showed that the percentages of students fulfilling the nutrient requirement after nutrition education were much higher than those at the baseline. The results of total fat, saturated fat, calcium, sodium and cholesterol were much improved after the nutrition education.

\section{Discussion and Recommendations}

From the course of work in this action research, the aim for implementing action learning in a primary school was successfully achieved. A participatory model blended with action and reflection for nutrition education is thus recommended. The support of parents and teachers is critical for success in achieving a desirable health outcome. For a long time, nutrition education and health education were considered as marginal subjects, or

Table 1. Degree of occurrence with sauce or gravy with high salt or fat content.

\begin{tabular}{cc}
\hline & Sauce or Gravy with High Salt or Fat Content \\
& N $(\%)$ \\
\hline Tse (Female, Obese) & $7(41.2)$ \\
Fong (Female, Non-Obese) & $13(76.5)$ \\
Chan (Male, Obese) & $2(11.8)$ \\
Yeung (Male, Non-Obese) & $3(17.6)$ \\
\hline
\end{tabular}

*Include fried rice or fried noodles.

Table 2. Paired samples statistics of daily energy requirement and daily energy consumption.

\begin{tabular}{cccc}
\hline $\mathrm{N}=4$ & Mean (Kcal) & SD & p-Value \\
\hline Pre-Intervention & & & \\
Daily Energy Requirement & 1834.2 & 302.8 & 0.417 \\
Daily Energy Consumption & 1923.3 & 400.5 & \\
Post-Intervention & & & \\
Daily Energy Requirement & 1697.5 & 199.0 & 0.615 \\
Daily Energy Consumption & 1667.5 & 240.5 & \\
\hline
\end{tabular}

Table 3. Comparisons between daily energy requirement and daily energy consumption before and after intervention.

\begin{tabular}{|c|c|c|c|c|c|c|c|c|c|}
\hline \multicolumn{2}{|c|}{$\mathrm{N}=4$} & \multicolumn{4}{|c|}{ Pre-Intervention } & \multicolumn{4}{|c|}{ Post-Intervention } \\
\hline $\begin{array}{l}\text { Student } \\
\text { Name }\end{array}$ & $\begin{array}{c}\text { Body Height } \\
\text { and Body } \\
\text { Weight } \\
\text { Standard }\end{array}$ & $\begin{array}{l}\text { Number of } \\
\text { Valid Dates }\end{array}$ & $\begin{array}{c}\text { Daily Energy } \\
\text { Requirement } \\
\text { (Kcal) }\end{array}$ & $\begin{array}{c}\text { Daily Energy } \\
\text { Consumption } \\
\text { (Kcal) }\end{array}$ & $\begin{array}{l}\text { Difference } \\
\text { (Kcal) }(\%)\end{array}$ & $\begin{array}{l}\text { Number of } \\
\text { Valid Dates }\end{array}$ & $\begin{array}{c}\text { Daily Energy } \\
\text { Requirement } \\
\text { (Kcal) }\end{array}$ & $\begin{array}{c}\text { Daily Energy } \\
\text { Consumption } \\
\text { (Kcal) }\end{array}$ & $\begin{array}{l}\text { Difference } \\
\text { (Kcal) }(\%)\end{array}$ \\
\hline Zhou & Obese & 5 & 2221.6 & 2173.5 & $-48.1(-2.2)$ & 11 & 1939.9 & 1727.8 & $-212.1(10.9)$ \\
\hline Yee & Obese & 7 & 1926.9 & 2027.8 & $100.9(5.2)$ & 11 & 1686.0 & 1652.2 & $-33.8(2.0)$ \\
\hline Hin & Not obese & 7 & 1618.6 & 2161.0 & $542.4(33.5)$ & 14 & 1453.1 & 1935.4 & $482.3(33.2)$ \\
\hline Man & Not obese & 7 & 1569.7 & 1330.8 & $-238.9(15.2)$ & 14 & 1712.3 & 1354.7 & $-357.6(20.9)$ \\
\hline
\end{tabular}

Paired sample t-test: mean $(\mathrm{SD})$ of pre-intervention $=89.1(332.7)$; mean $(\mathrm{SD})$ of post-intervention $=-30.3(366.5) ; \mathrm{p}=0.012$. 


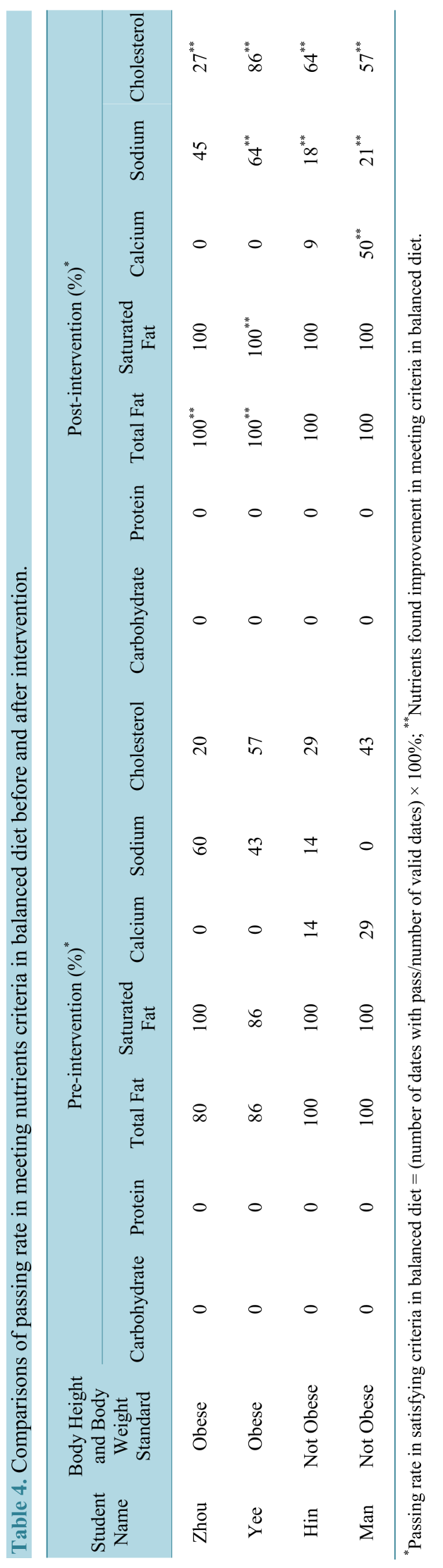


supplementary to general subjects in the school curriculum [23]. With the emerging health problems such as childhood obesity, it is high time for schools to put more emphasis on nutrition education in order to restore healthy lifestyle of the children. In this study, the results showed that the eating behaviour could be modified by participatory approaches blended in nutrition education. It was not just a class-directed teaching, but an activity-based real life practice. For the example the food image taking as the dietary intake records was applied in the pedagogy. Through the web-based dietary recording platform, analysis of diet could be shown online and students could reflect their food choice with individualized energy requirement. Students could become more aware of what they should eat and how much they should eat, and be cautious to the consequences of poor food choices. Corrective action on healthy food choice was the desired learning to the students.

From the review of meal menu order forms, it was found that all four subjects did not eat vegetable every lunch meal, disregard to the number of serving which could not be assessed solely by the name of menu. The emphasis on consuming whole grains and the recommendations on avoiding the "limited" food items and the "strongly discouraged" food items were found ignored by the school teachers, lunch box providers, parents and the students. These findings suggested that the lunch provider and the school were either not aware of the lunch assessment criteria or they did not know how to modify the menu so as to meet the criteria. Another possible reason was the students and the parents did not have the nutrition knowledge in choosing healthy food from the meal menu.

Besides, it is the common problem of Chinese food containing sauce or gravy with high salt or fat content. It could be a cultural problem because Chinese people preferred food mixed with sauce or soup and Chinese sauce or gravy are usually prepared with high sodium, high saturated fat or high sugar level. This eating style further complicated with the consideration in profit taking and easiness in food preparation for the lunch providers that the sauces made typically relied on highly seasoned gravies, sugar and oil. The students inevitably absorbed more fat and calories than they required.

\section{Limitation}

As the participated students in this study were the primary 6 students, whose eating behaviors and cognitive learning in nutrition education could be different from those of lower grades students. In addition, the number of students involved was small. The findings observed in this study thus could not be generalized to the entire nutrition curriculum in elementary education. However, a nutrition education targeting higher grade elementary students helps giving them a right concept in healthy eating before they move to the age of adolescents.

\section{Conclusion and Implications}

In this action research, we established a participatory model for school teachers to design nutrition education pedagogy for addressing the childhood obesity problem. A blended action and reflection learning was found feasible and could be effective in modifying the eating behaviour of primary school children. The findings of this action research laid valuable foundations in future action research on nutrition education.

\section{References}

[1] Baur, L., Lobstein, T. and Uauy, R. (2004) Obesity in Children and Young People: A Crisis in Public Health. Obesity Reviews, 5, 4-85. http://dx.doi.org/10.1111/j.1467-789X.2004.00133.x

[2] Lobstein, T. and Frelut, M.L. (2003) Prevalence of Overweight among Children in Europe. Obesity Reviews, 4, 195200. http://dx.doi.org/10.1046/j.1467-789X.2003.00116.x

[3] Cole, T.J., Bellizzi, M.C., Flegal, K.M. and Dietz, W.H. (2000) Establishing a Standard Definition for Child Overweight and Obesity Worldwide: International Survey. British Medical Journal, 320, 1240-1243. http://dx.doi.org/10.1136/bmj.320.7244.1240

[4] Group of China Obesity Task Force (2004) Body Mass Index Reference Norm for Screening Overweight and Obesity in Chinese Children and Adolescents. Zhonghua Liu Xing Bing Xue Za Zhi, 25, 97-102. http://www.ncbi.nlm.nih.gov/pubmed/15132858

[5] Ogden, C.L., Kuczmarski, R.J., Flegal, K.M., Mei, Z., Guo, S., Wei, R., Grummer-Strawn, L.M., Curtin, L.R., Roche, A.F. and Johnson, C.L. (2002) Centers for Disease Control and Prevention 2000 Growth Charts for the United States: Improvements to the 1977 National Center for Health Statistics Version. Pediatrics, 109, 45-60.

http://dx.doi.org/10.1542/peds.109.1.45 
[6] Leung, S.S.F., Lau, J.T.F., Tse, L.Y. and Oppenheimer, S.J. (1996) Weight-for-Age and Weight-for-Height References for Hong Kong Children from Birth to 18 Years. Journal of Paediatrics and Child Health, 32, 103-109. http://dx.doi.org/10.1111/j.1440-1754.1996.tb00904.x

[7] Department of Health, Government of Hong Kong Special Administrative Region (2007) Baseline Assessment of Promoting Healthy Eating in Primary Schools: Supplementary Report on School Lunch. http://www.chp.gov.hk/files/pdf/grp supplementary report on school lunch en 20061003.pdf

[8] Hill, A.J. and Silver, E.K. (1995) Fat, Friendless and Unhealthy: 9-Year Old Children's Perception of Body Shape Stereotypes. International Journal of Obesity and Related Metabolic Disorders, 19, 423-430.

[9] Hui, L.L., Nelson, E.A.S., Yu, L.M., Li, A.M. and Fok, T.K. (2003) Risk Factors for Childhood Overweight in 6- to 7-Year-Old Hong Kong Children. International Journal of Obesity and Related Metabolic Disorders, 27, 1411-1418. http://dx.doi.org/10.1038/sj.ijo.0802423

[10] Csabi, G., Torok, K., Jeges, S. and Molnar, D. (2000) Presence of Metabolic Cardiovascular Syndrome in Obese Children. European Journal of Pediatrics, 159, 91-94. http://dx.doi.org/10.1007/PL00013812

[11] Lumeng, J.C., Gannon, K., Cabral, H.J., Frank, D.A. and Zuckerman, B. (2003) Association between Clinically Meaningful Behavior Problems and Overweight in Children. Pediatrics, 112, 1138-1145. http://dx.doi.org/10.1542/peds.112.5.1138

[12] Cornette, R. (2008) The Emotional Impact of Obesity on Children. Worldviews on Evidence-Based Nursing, 5, 136141. http://dx.doi.org/10.1111/j.1741-6787.2008.00127.x

[13] Hill, A.J., Draper, E. and Stack, J. (1994) A weight on Children's Minds: Body Shape Dissatisfactions at 9 Years Old. International Journal of Obesity and Related Metabolic Disorders, 18, 383-389.

[14] Chen, W., Bao, W., Begum, S., Elekasabany, A., Srinivasan, S.R. and Berenson, G.S. (2000) Age-Related Patterns of the Clustering of Cardiovascular Risk Variables of Syndrome X from Childhood to Young Adulthood in a Population Made Up of Black and White Subjects: The Bogalusa Heart Study. Diabetes, 49, 1042-1048. http://dx.doi.org/10.2337/diabetes.49.6.1042

[15] Freedman, D.S., Mei, Z., Srinivasan, S.R., Berenson, G.S. and Dietz, W.H. (2007) Cardiovascular Risk Factors and Excess Adiposity among Overweight Children and Adolescents: The Bogalusa Heart Study. Journal of Pediatrics, 150, 12-17.e2. http://dx.doi.org/10.1016/j.jpeds.2006.08.042

[16] Kong, A.P., Choi, K.C., Ko, G.T., Wong, G.W., Ozaki, R., So, W.Y., Tong, P.C. and Chan, J.C. (2008) Associations of Overweight with Insulin Resistance, Beta-Cell Function and Inflammatory Markers in Chinese Adolescents. Pediatric Diabetes, 9, 488-495. http://dx.doi.org/10.1111/j.1399-5448.2008.00410.x

[17] National Heart Lung and Blood Institute (1998) Clinical Guidelines on the Identification, Evaluation, and Treatment of Overweight and Obesity in Adult. The Evidence Report 1998, National Institutes of Health, USA, 1.

[18] Gerald, I.S. (1983) Action Research: A Sociotechnical Systems Perspective. Edited by Morgan, G., Sage Publications, London, 102.

[19] Spalding, N.J. (2009) Improving Practice through Involvement in Action Research. International Journal of Therapy and Rehabilitation, 16, 130-138. http://dx.doi.org/10.12968/ijtr.2009.16.3.40065

[20] Hart, E. and Bond, M. (1995) Action Research for Health and Social Care: A Guide to Practice. Open University Press, Buckingham.

[21] Chung, L.M.Y. and Chung, J.W.Y. (2010) Tele-Dietetics with Food Images as Dietary Intake Records in Nutrition Assessment. Telemedicine and e-Health, 16, 691-698. http://dx.doi.org/10.1089/tmj.2009.0174

[22] Chung, L.M.Y., Chung, J.W.Y. and Wong, T.K.S. (2009) Usability Test of an Interactive Dietary Recording. Global Journal of Health Education and Promotion, 12, 123-134.

[23] Johns, D.P. and Shuttleworth, J.J. (1996) Present Practices, Future Discourses: Addressing Context and Relevancy of Contemporary Professional Practice. Journal of Primary Education, 6, 57-65. 


\section{Appendix I: Checklist for Meal Observation}

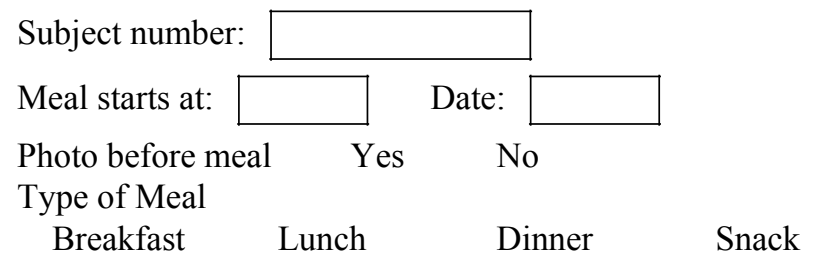

Part 1: Food/Drink Intake (to Be Completed by Researcher)

1. Number of food items in lunch box: , go to $1 \mathrm{a}$

1a. List food item (and amount):

2. Any fluid intake:

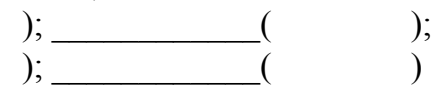

$\square$ Yes, go to $2 \mathrm{a}$ and $2 \mathrm{~b} \quad$ No

2a. When to drink:

$\square$ before the main course during the main course after the main course 2b. Type (and amount) of drinks:

3. Any fruit intake:

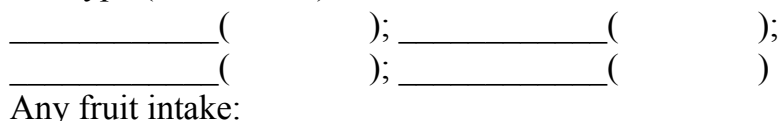

$\square$ Yes, go to $3 \mathrm{a} \quad$ No

3a. Type (and amount) of fruits:

4. Any second helpings:

$\longrightarrow(1)$

$\square$ Yes, go to $4 \mathrm{a}$ and $4 \mathrm{~b} \quad$ No

4a. The frequency of second helpings:

4b. List food item (and amount) of second helpings:

5. Any left over:

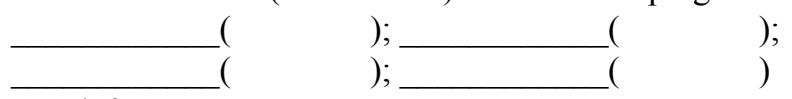

$\square$ Yes, go to $5 \mathrm{a} \quad$ No

5a. The type (and amount) of food left uneaten:

$\longrightarrow(1)$

Part 2: Eating Behaviour (to Be Completed by Researcher)

6. Bites and chews

Overall bites: small acceptable big

Overall chews: slow acceptable fast

7. Stay in seat during meal time seldom sometimes always

8. Chatting during the meal time

$\square$ seldom sometimes always

9. Distractions during the meal/snack time

$\square$ Yes, go to 9a No

9a. Extent of distractions

$\square$ Nearly $100 \%$ of the time

Less than $50 \%$ of the time

About $50 \%$ of the time

Specify distraction and extraneous response: 
Part 3: General Complexion (to Be Completed by Subject. Subject Is Asked to Put X on the Time That Best Reflect Their Feeling)

12. Tense Very tense

13. Happiness Very happy

\begin{tabular}{|l|l|l|l|l|l|l|l|l|l|}
\hline 10 & 9 & 8 & 7 & 6 & 5 & 4 & 3 & 2 & 1 \\
\hline
\end{tabular}

14. Food enjoymen Very enjoy

\begin{tabular}{|l|l|l|l|l|l|l|l|l|l|}
\hline 10 & 9 & 8 & 7 & 6 & 5 & 4 & 3 & 2 & 1 \\
\hline
\end{tabular}

\begin{tabular}{|l|l|l|l|l|l|l|l|l|l|}
\hline 10 & 9 & 8 & 7 & 6 & 5 & 4 & 3 & 2 & 1 \\
\hline
\end{tabular}

\section{Part 4: Other Observations (to Be Completed by Researcher)}

15. Other observations:

yes (specify:

no

Meal finished at

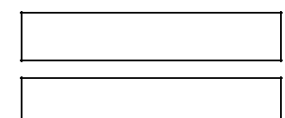

Photo after meal

Yes No

Total meal time

What does he/she do after meal and before recess?

Name and signature of the researcher

\section{Appendix 2: Criteria Used to Assess the Healthiness of Lunch Menus}

\begin{tabular}{cl}
\hline Criteria & \multicolumn{1}{c}{ Requirement } \\
\hline I & Vegetables are mentioned in all lunch choices on every school day \\
II & Whole grains are mentioned in at least one lunch choice on every school day \\
III & Reduced fat dairy products or other calcium-rich food items are mentioned in at least one lunch choice on every school day \\
IV & Limited food items are served in no more than two school days \\
V & No strongly discouraged food items are found on all school days \\
\hline
\end{tabular}

